\title{
CONCEPTUAL ISSUES REGARDING REVERSE LOGISTICS
}

\author{
Ioana Olariu \\ "Vasile Alecsandri” University of Bacau \\ ioana_barin_olariu@yahoo.com
}

\begin{abstract}
As the power of consumers is growing, the product return for customer service and customer retention has become a common practice in the competitive market, which propels the recent practice of reverse logistics in companies. Many firms attracted by the value available in the flow, have proactively participated in handling returned products at the end of their usefulness or from other parts of the product life cycle. Reverse logistics is the flow and management of products, packaging, components and information from the point of consumption to the point of origin. It is a collection of practices similar to those of supply chain management, but in the opposite direction, from downstream to upstream. It involves activities such as reuse, repair, remanufacture, refurbish, reclaim and recycle. For the conventional forward logistics systems, the flow starts upstream as raw materials, later as manufactured parts and components to be assembled and continues downstream to reach customers as final products to be disposed once they reach their economic or useful lives. In reverse logistics, the disposed products are pushed upstream to be repaired, remanufactured, refurbished, and disassembled into components to be reused or as raw material to be recycled for later use.
\end{abstract}

\section{Keywords}

Logistics; supply chain; reverse flows; network.

\section{JEL classification}

M31

\section{Introduction}

Because the reverse logistics is driven by two guidelines, of profit and legal regulation, it becomes more complex than the forward distribution system, in terms of managing, controlling and processing. Guide et al (2001) studied seven characteristics that distinguish reverse supply systems from the features of forward logistics:

- Return uncertain timing and quantity of returns, which adds a degree of unrest to demand management and inventory control.

- A need to balance returns. Too many items returned will cause a firm to penalize unnecessary port inventory cost.

- Disassembly is a necessary process in remanufacturing, but the rate of recovery is uncertain, which brings difficulty to control sequential operations.

- Uncertainty in materials recovered from returned items, which raises the question of coordinating inventory.

- The requirement for a reverse logistics network. Companies should establish collection centers and remanufacturing centers to coordinate the return and remanufacturing process.

- Complication of material matching restrictions. Customers often require some components of the product and will cause a problem that customer satisfaction when a part is not obtained.

- Stochastic routing problems for materials in the repair and remanufacturing operations. This feature will bring in variability in operation causes coordination and control problem in reverse operation. 
In addition to these operational differences between forward and reverse supply systems, conceptual system is a system before firing, while the reverse system is both a pull and push (Krikke, 1998).

In the forward system, the eventual goal is to serve the end customers, while in a reverse system the targets are secondary customer groups, and firms have to implement obligatory returning process from the end-use customers. Therefore much coordination and adjustment are necessary in implementing the push and pull systems in reverse logistics.

In the literature, there have been several streams of research on issues relating to reverse flows. These include reverse flow network design, inventory control for profits, closed-loop supply chain, green supply chains.

\section{Components of reverse logistics}

\subsection{Return type}

Products, parts and materials are frequently reverse logistics cycle for different reasons at different points in the life cycle of the product of each element. There are four major returns in practice (Krikke et al, 2004):

- End of life return (EOL): this return takes place when the product life cycle of the item comes to an end.

- Commercial return: the reasons that these returns are made include wrong orders, customer dissatisfaction, defects, problems with installation etc.

- End of use return: this category encompasses returned items after some period of operation due to end of lease, trade-in or product replacement. The products may be refurbished or repaired to be sold in an alternative market or in a geographically different market.

- Reusable items: products in this classification are separate parts of major products such as reusable containers and pallets, recycled toner bottles, etc.

There have also been many studies on inventory control for reverse flows, aiming at integrating the reverse flow into the manufacturers' materials planning.

\subsection{Recovery options}

The first step in reverse logistics with respect to recovery program is to collect the items. Firms have different collection systems and strategies contingent on the type of product. With the products collected, firms sort the items based on the condition of the product (Jayaraman, 2006).

Then companies seek to extract value out of the products or components as much as possible by assigning the returned items into an appropriate recovery method. Based on the literature, the recovery options are: reuse, remanufacturing and recycling.

Reverse logistics is concerned with planning decisions and scheduling issues involved in manufacturing, warehousing, shipping, collection and reprocessing of used products, damaged products, unwanted products, outdated products and shipping/packaging materials.

There are various reasons why those products are taken back instead of being thrown away: they can be recycled to get reusable raw materials; after refurbishment or repair, they can be resold on the market to gain more profit, they have to be reprocessed to comply with government regulations and environmental law etc.

\subsection{Secondary market}

New products are generally transacted in the primary market. The channel process of the primary market, as described by the forward supply chain system, is that flows are 
from factory to manufacturer's distribution center, to retailer distribution center, to the store, and then to the end customer.

However, some retailers or remanufacturers face how they have to sell remanufactured products since the markets for used products are subdivisions of the primary market and are interwined.

A secondary market is defined as a selling channel outside of the primary market, mainly to salvage or overstock brokers (Tibben-Lembke, 2004). Even though, secondary markets are important transaction places, the structure or sales channels in the secondary markets have not been well documented in comparison to the operational aspects of the reverse supply chains system.

\subsection{Network design for reverse flows}

Even though network formulation in the context of forward flow systems has been widely studied, the system performing forward activities in a traditional supply chain is not directly applicable to the network structure of reverse logistics since the forward flow system is nor originally designed to handle returned products.

Due to on-equipment of handling return products in the forward system and different cost structures, such as the costs of collecting, classifying, testing and disassembling returned goods that occur only in the reverse channel but not in the forward system (Jayataman, 1999).

Fleischmann et al (1997) also indicated that the reverse channel is not necessarily a symmetric picture of forward distribution.

The studies on network design for reverse flows mainly focus on the design of logistics structures for shipping used/returned products back to the facilities.

Among the more recent results, Fleischmann et al $(2000,2001)$ studied the network design problems and analyzed the impact of reverse flows on network designs and operational performance of a supply chain.

The general processes associated with reverse logistics are described as follows (Fleischmann et al, 1997):

- Collection: refers to all activities rendering used products available and physically moving them to some point for further treatment. Collection may include purchasing, transportation and storage activities.

- Inspection/separation: denotes all operations which determine whether a given product is in fact reusable and in which way. Thus, inspection and separation result in splitting the flow of used products according o distinct reuse options. Inspection and separation may encompass disassembly, shredding, testing, sorting and storage steps.

- Re-processing: means the actual transformation of a used product into a usable product again. This transformation may take different forms including recycling, repair and remanufacturing. In addition, activities such as cleaning, replacement and reassembly may be involved.

- Disposal: is required for products that cannot be re-used for technical or cost reasons. This applies to products rejected at the separation level due to excessive repair requirements but Also to products without satisfactory market potential, due to obsolescence. Disposal may include transportation, landfilling and incineration steps.

- Re-distribution: refers to directing reusable products to a potential market and to physically moving them to future users. This may include sales, transportation and storage activities. 


\section{Closed-loop supply chains and green supply chains}

Most existing studies on closed-loop supply chains focus on management strategies and policies. The research on green supply chains focuses heavily on environmental issues, the linkages between the operations policies of supply chain partners, and the activities performed by plant managers, suppliers, and customers. Reverse logistics is a growing area in logistics management. Concern about environmental issues such as pollution, traffic congestion, global warning, disposal and clean-up hazardous materials has led to a number of environmental laws and EU directives that affect logistics systems design and strategies. Thus reverse logistics can be defined as: "the process of planning, implementing and controlling the efficient, cost effective flow of raw materials, in-process inventory, finished goods and related information from the point of consumption to the point of origin for the purpose of recapturing value or proper disposal”.

Essentially, reverse logistics is the process of moving goods from their point of consumption to the appropriate link in the supply chain for the purpose of capturing any residual value through remanufacturing or refurbishing, or the proper disposal. Thus, reverse logistics management represents a systematic business model, to profitably close the loop on the supply chain. But, reverse logistics is not only about reusing containers, recycling packaging materials, redesigning packaging to use less material, or reducing the energy use and pollution that results from transportation. These activities, while important, are more in the realm of green logistics. If goods or materials are not sent backwards through the supply chain, then an activity is probably not a reverse logistics activity.

Reverse logistics also includes processing returned merchandise due to damage, seasonal inventory, restock, salvage, recalls and excess inventory.

Key management elements in reverse logistics include the following:

- Gatekeeping to screen defective and unwarranted returned merchandise at the entry point into the reverse logistics process.

- Short disposition cycle times related to return product decisions, movement and processing to avert a lengthy ageing process on returns.

- Reverse logistics information systems to properly track returns, and measure disposition cycle times and vendor performance.

- Central return centers or processing facilities dedicated to handling returns quickly and efficiently.

- Zero returns policies that avoid accepting any physical returns and instead set maximum values of returned products that are payable to customers.

- Remanufacture and refurbishment of products, which has the following categories: repair, refurbishing and remanufacturing to recondition or upgrade products, and cannibalization and recycling to use or dispose of products.

- Asset recovery classifies and disposes returned goods, surplus, obsolete, scrap, waste and excess material products, and other assets, to maximize returns to the owner, and minimize the costs and liabilities associated with disposition.

- Negotiation of the value of returned material without any pricing guidelines. This task is often performed by specialist third parties, who advise the primary participants in the supply chain who are working to transfer ownership of the material back to the original source.

- Financial management policies to properly handle accounting and reconciliation issues related to returned products.

- Outsourcing reverse product flow, to reverse logistics outsource suppliers who can be used as a benchmark to help determine what and how reverse activities should be performed and how much those activities should cost.

Reverse logistics reduces the amount of waste disposed into the environment, thus, reducing the reliance on landfills and energy. Saving energy is another valuable 
environmental motive. Many companies today want to appeal to their customers as being "environmentally responsible", a part of their marketing image. This has become more pressing as customers became selective of green and/or environmentally friendly products.

Public environmental concern, coupled with sustainable development, has created opportunities for organizations to differentiate their products from their competitors by being "greener" (Johnson, 1998).

The need to consider reverse and green logistics has also seen the growth of thirdparty reverse logistics providers who assist companies to meet new guidelines and enhance their business opportunities.

Environmental concerns about packaging, recyclability and reusability are becoming more important, and the implementation and management of reverse logistics will also affect logistics decision-making in the future.

\section{In conclusion}

Implementing reverse logistics has numerous benefits. These benefits are economical, environmental, marketing image, market share and exposure, and asset protection. The main motive behind reverse logistics is economical - minimizing cost and increasing profits. Reverse logistics is a chance to recapture value from returned products through recovery/reuse/repair options. Beside reducing cost, many organizations take back their competitors products in addition to theirs as a strategy to increase their market share. Some companies offer to collect all brands of a certain product in exchange for a price discount for the company's own brand.

Critical success factors for reverse logistics programmes to capture the key elements above include the following: management and control by mapping or flowcharting the reverse logistics process through the suppliers and other supply chain members, and developing partnerships to achieve reverse logistics goals and economies of scale; measurement by adopting full product life cycle and end of product life costing as they relate to reverse logistics activities and the product supply chain and finance to properly allocate sufficient resources for reverse logistics activities and environmental initiatives.

\section{References}

Blumberg, D.F. (2005) Introduction to Management of Rverse Logistics and Closed Loop Supply Chain Processes, CRC Press.

Bowersox, D.J., Closs, D.J. \& Cooper, M.B. (2002) Supply Chain Logistics Management, New York, NY: McGraw Hill.

Dale, R.S. Tibben-Lembke, R.S. (1998) Going backwords: Reverse logistics Trends and Practices, University of Nevada-Reno: Reverse Logistics Executive Council.

Dyckhoff, H., Lackes, R. \& Reese, J. (2004) Supply Chain Management and Reverse Logistics, Berlin Heidelber: Springer-Verlag.

Fleeischmann, M., (2001) Reverse logistics network structure and design, Rotterdam, The Netherlands: ERIM Report Series Research in Management.

Grant, D.B.; Lambert, D.M.; Stock, J.R.; Ellram, L.M. (2006) Fundamentals of Logistics Management, McGraw-Hill Education;

Johnson, P.F. (1998) "Managing value in reverse logistics systems", Transportation Research Part E: Logistics and Transportation Review, 34 (3), 217-227. 
Tibben-Lembke, R.S.; Dale, R.S., (2002), "Differences between forward and reverse logistics in a retail environment”, Supply Chain Management: An International Journal 7, 5, 271-282.

Stock, (1998) Development and Implementation of Reverse Logistics Programs, 9-10, 20. 